\title{
Progress Toward Maternal and Neonatal Tetanus Elimination - Worldwide, 2000-2018
}

\author{
Henry N. Njuguna, MD¹; Nasir Yusuf, MD²; Azhar Abid Raza, MD³; Bilal Ahmed, MBBS 3 ; Rania A. Tohme, MD $^{1}$
}

Maternal and neonatal tetanus* (MNT) remains a major public health problem, with an $80 \%-100 \%$ case-fatality rate among neonates, especially in areas with poor immunization coverage and limited access to clean deliveries (i.e., delivery in a health facility or assisted by medically trained attendants in sanitary conditions) and umbilical cord care (1). In 1989, the World Health Assembly endorsed the elimination ${ }^{\dagger}$ of neonatal tetanus (NT), and in 1999, the initiative was relaunched and renamed the MNT elimination ${ }^{\S}$ initiative, targeting 599 priority countries (1). Elimination strategies include 1 ) achieving $\geq 80 \%$ coverage with $\geq 2$ doses of tetanus toxoidcontaining vaccine (TTCV) among women of reproductive age through routine immunization of pregnant women and supplementary immunization activities (SIAs)** in high-risk areas and districts ${ }^{\dagger \dagger}$; 2) achieving care at $\geq 70 \%$ of deliveries by a skilled birth attendant (SBA) $)^{\S \$}$; and 3 ) enhancing surveillance for NT cases (1). This report summarizes progress toward achieving MNT elimination during 2000-2018. Coverage with $\geq 2$ doses of TTCV ( 2 doses of tetanus toxoid [TT2+] or 2 doses of tetanus-diphtheria toxoid $[\mathrm{Td} 2+]$ ) among women of reproductive age increased by $16 \%$, from $62 \%$ in 2000 to $72 \%$ in 2018. By December 2018, 52 (88\%) of 59 priority countries had conducted TTCV SIAs, vaccinating 154 million (77\%) of 201 million targeted women of reproductive age with $\mathrm{TT} 2+/ \mathrm{Td} 2+$. Globally, the percentage of deliveries assisted

\footnotetext{
* Maternal tetanus is defined as tetanus occurring during pregnancy or within 6 weeks of the end of pregnancy (birth, miscarriage, or abortion). Maternal tetanus infection occurs during abortion, miscarriages, or unhygienic delivery. Neonatal tetanus occurs during the first 28 days of life; neonatal tetanus infection occurs following cutting the umbilical cord under nonsterile conditions or applying nonsterile traditional remedies to the umbilical stump in an infant without passively (transplacentally) acquired maternal antibodies.

$\dagger$ Neonatal tetanus (NT) elimination is defined as the occurrence of less than one NT case per 1,000 live births per year in every district in every country.

$\S \mathrm{NT}$ elimination is considered a proxy for maternal tetanus elimination, and both share the same strategies for elimination.

Initially, the total number of priority countries was 57 . The creation of TimorLeste in 2002 and South Sudan in 2011 increased the number of priority countries to 59 .

** SIAs are mass vaccination campaigns that aim to administer doses of tetanuscontaining vaccines to women of childbearing age.

${ }^{\dagger}$ High-risk areas and districts are defined as those in which the estimated NT case rate exceeds 1 per 1,000 live births, clean delivery coverage is less than $70 \%$, and coverage with at least 3 tetanus toxoid-containing vaccine (TTCV) doses among pregnant women or women of reproductive age is less than $80 \%$ during the past 5 years.

$\$ \$$ A skilled birth attendant is defined as a midwife, trained nurse, doctor, or a health extension or community health worker.
}

by SBAs increased from 62\% during 2000-2005 to $81 \%$ during 2013-2018, and estimated neonatal tetanus deaths decreased by $85 \%$, from 170,829 in 2000 to 25,000 in 2018 . By December 2018, 45 (76\%) of 59 priority countries were validated by WHO as having achieved MNT elimination. To achieve elimination in the remaining 14 countries and sustain elimination in countries that have achieved it, implementation of MNT elimination strategies needs to be maintained and strengthened, and TTCV booster doses need to be included in country immunization schedules as recommended by the World Health Organization (WHO) (2). In addition, integration of maternal, newborn, and child health services with vaccination services is needed, as well as innovative approaches to target hard-to-reach areas for tetanus vaccination and community engagement to strengthen surveillance.

\section{Immunization Activities}

To estimate $\mathrm{TT} 2+/ \mathrm{Td} 2+$ vaccination coverage delivered through routine immunization services and the number of neonates protected at birth (PAB) 99 from neonatal tetanus, WHO and the United Nations Children's Fund (UNICEF) use data from administrative records and vaccination coverage surveys reported annually by member countries (3). WHO and UNICEF also receive summaries of the number of women of reproductive age receiving TTCV during SIAs (4). During 2000-2018, coverage worldwide of women of reproductive age with $\mathrm{TT} 2+/ \mathrm{Td} 2+$ increased by $16 \%$, from $62 \%$ to $72 \%$ (3). In 2018,17 (29\%) of 59 priority countries achieved TT $2+/ \mathrm{Td} 2+$ coverage $\geq 80 \%$; in 39 of $48(81 \%)$ priority countries where data were available, ${ }^{* * *} \mathrm{TT} 2+/ \mathrm{Td} 2+$ coverage increased compared with that in 2000. In 2018, the percentage of infants who were $\mathrm{PAB}$ was $\geq 80 \%$ in 46 (78\%) of 59 priority countries (Table).

By the end of 2018, 52 (88\%) of 59 priority countries had conducted TTCV SIAs, and 154 million (77\%) of the

\footnotetext{
99 Protected at birth $(\mathrm{PAB})$ is defined as the status of an infant born to a mother who received 2 doses of tetanus toxoid or tetanus-diphtheria toxoid (TT/Td) during the last birth; 2 or more TT/Td doses, with the last dose received $\leq 3$ years before the last delivery; 3 or more doses with the last dose received $\leq 5$ years earlier; 4 or more doses with the last dose received $\leq 10$ years earlier; or receipt of 5 or more previous doses.

*** Angola, Burkina Faso, China, Egypt, Guinea Bissau, Haiti, Mauritania, Nigeria, Rwanda, Timor-Leste, South Africa, and South Sudan had missing $\mathrm{TT} 2+/ \mathrm{Td} 2+$ coverage data for the year 2000 or 2018
} 
TABLE. Estimated coverage with $\geq 2$ doses of tetanus toxoid-containing vaccine (TTCV) among women of reproductive age (WRA) administered through routine immunization services, estimated percentage of newborns protected at birth (PAB), number of WRA vaccinated with TTCV during supplementary immunization activities (SIAs), percentage of deliveries attended by a skilled birth attendant (SBA), and number of reported neonatal tetanus cases - 59 priority countries, 2000-2018

\begin{tabular}{|c|c|c|c|c|c|c|c|c|c|c|c|c|c|c|}
\hline \multirow{3}{*}{$\begin{array}{l}\text { MNT } \\
\text { elimination } \\
\text { priority } \\
\text { countries }\end{array}$} & \multicolumn{3}{|c|}{$\begin{array}{l}\text { WRA TT2+/Td2+ } \\
\text { coverage }(\%)\end{array}$} & \multicolumn{3}{|c|}{ Newborns PAB (\%) } & \multicolumn{2}{|c|}{$\begin{array}{l}\text { WRA vaccinated during } \\
\text { TTCV SIAs* }\end{array}$} & \multicolumn{3}{|c|}{$\begin{array}{c}\text { SBA attendance at } \\
\text { delivery (\%) }\end{array}$} & \multicolumn{3}{|c|}{ No. of neonatal tetanus cases } \\
\hline & \multicolumn{2}{|c|}{ Year } & \multirow{2}{*}{$\begin{array}{c}\text { Change } \\
2000-2018 \\
(\%)\end{array}$} & \multicolumn{2}{|c|}{ Year } & \multirow{2}{*}{$\begin{array}{c}\text { Change } \\
2000-2018 \\
(\%)\end{array}$} & \multirow{2}{*}{$\begin{array}{c}\text { No. of } \mathrm{TT}_{2+}^{+} / \\
\mathrm{Td} 2+\text { doses } \\
\text { received }\end{array}$} & \multirow{2}{*}{$\begin{array}{c}\% \\
\text { vaccinated }\end{array}$} & \multicolumn{2}{|c|}{ Year $^{\dagger}$} & \multirow{2}{*}{$\begin{array}{c}\text { Change } \\
2000-2018 \\
(\%)\end{array}$} & \multicolumn{2}{|c|}{ Year } & \multirow{2}{*}{$\begin{array}{c}\text { Change } \\
2000-2018 \\
(\%)\end{array}$} \\
\hline & 2000 & 2018 & & 2000 & 2018 & & & & 2000 & 2018 & & 2000 & 2018 & \\
\hline \multicolumn{15}{|c|}{ Validated for MNT elimination by end-2018 } \\
\hline Bangladesh & 89 & 97 & 9 & 89 & 98 & 10 & $1,438,374$ & 47 & 12 & 68 & 467 & 376 & 84 & -78 \\
\hline Benin & 81 & 69 & -15 & 87 & 85 & -2 & $1,399,461$ & 97 & 66 & 78 & 18 & 52 & 13 & -75 \\
\hline Burkina Faso & NA & 92 & NA & 57 & 92 & 61 & $2,306,835$ & 91 & 38 & 80 & 111 & 22 & 3 & -86 \\
\hline Burma & 81 & 89 & 10 & 79 & 90 & 14 & $8,170,763$ & 87 & 57 & 60 & 5 & 41 & 22 & -46 \\
\hline Burundi & 28 & 90 & 221 & 51 & 90 & 76 & 679,222 & 55 & 25 & 85 & 240 & 16 & 0 & -100 \\
\hline Cambodia & 40 & 75 & 88 & 58 & 93 & 60 & $2,099,471$ & 79 & 32 & 89 & 178 & 295 & 14 & -95 \\
\hline Cameroon & 40 & 66 & 65 & 54 & 85 & 57 & $2,687,461$ & 85 & 56 & 65 & 16 & 279 & 27 & -90 \\
\hline China & NA & NA & NA & NA & NA & NA & NA & NA & 97 & 100 & 3 & 3230 & 83 & -97 \\
\hline Comoros & 40 & 78 & 95 & 57 & 85 & 49 & 160,767 & 55 & 62 & NA & NA & NA & 1 & NA \\
\hline Congo & 39 & 83 & 113 & 67 & 85 & 27 & 273,003 & 91 & 83 & 91 & 10 & 2 & 0 & -100 \\
\hline Côte d'Ivoire & 78 & 85 & 9 & 76 & 85 & 12 & $5,924,527$ & 85 & 63 & 74 & 17 & 30 & 17 & -43 \\
\hline Egypt & 71 & NA & NA & 80 & 86 & 7 & $2,518,802$ & 87 & 61 & 92 & 51 & 321 & 2 & -99 \\
\hline $\begin{array}{l}\text { Equatorial } \\
\text { Guinea }\end{array}$ & 30 & 41 & 37 & 61 & 70 & 15 & 26,466 & 9 & 65 & NA & NA & NA & 6 & NA \\
\hline Eritrea & 25 & 65 & 160 & 80 & 99 & 24 & NA & NA & 28 & NA & NA & 4 & 0 & -100 \\
\hline Ethiopia & 32 & 87 & 172 & 54 & 93 & 72 & $13,210,107$ & 84 & 6 & 16 & 167 & 20 & 14 & -30 \\
\hline Gabon & 16 & 50 & 213 & 39 & 85 & 118 & 79,343 & 90 & 86 & NA & NA & 8 & 0 & -100 \\
\hline Ghana & 73 & 64 & -12 & 69 & 89 & 29 & $1,666,666$ & 87 & 47 & 78 & 66 & 80 & 9 & -89 \\
\hline Guinea Bissau & NA & NA & NA & 49 & 83 & 69 & 312,669 & 98 & 32 & 45 & 41 & NA & 0 & NA \\
\hline Haiti & NA & NA & NA & 41 & 81 & 98 & $2,785,588$ & 88 & 24 & 42 & 75 & 40 & 3 & -93 \\
\hline India & 80 & 81 & 1 & 85 & 90 & 6 & $7,643,440$ & 94 & 43 & 81 & 88 & 3287 & 129 & -96 \\
\hline Indonesia & 81 & 47 & -42 & 82 & 85 & 4 & $1,442,264$ & 50 & 66 & 94 & 42 & 466 & 14 & -97 \\
\hline Iraq & 55 & 49 & -11 & 75 & 75 & 0 & 111,721 & 96 & 65 & 96 & 48 & 37 & 3 & -92 \\
\hline Kenya & 51 & 61 & 20 & 68 & 88 & 29 & $4,463,695$ & 67 & 42 & 62 & 48 & 1278 & NA & NA \\
\hline Laos & 45 & 37 & -18 & 58 & 90 & 55 & 968,323 & 90 & 17 & 64 & 276 & 21 & 16 & -24 \\
\hline Liberia & 25 & 74 & 196 & 51 & 89 & 75 & 288,984 & 57 & 51 & 61 & 20 & 152 & 14 & -91 \\
\hline Madagascar & 40 & 51 & 28 & 58 & 78 & 34 & $2,705,588$ & 72 & 47 & 44 & -6 & 13 & 30 & 131 \\
\hline Malawi & 61 & 67 & 10 & 84 & 89 & 6 & NA & NA & 56 & 87 & 55 & 12 & 9 & -25 \\
\hline Mauritania & NA & 31 & NA & 44 & 80 & 82 & 586,277 & 76 & 53 & 69 & 30 & NA & 0 & NA \\
\hline Mozambique & 61 & 85 & 39 & 75 & 86 & 15 & 605,640 & 79 & 48 & 73 & 52 & 42 & 160 & 281 \\
\hline Namibia & 60 & 76 & 27 & 74 & 88 & 19 & NA & NA & 76 & 88 & 16 & 10 & 0 & -100 \\
\hline Nepal & 60 & 75 & 25 & 67 & 89 & 33 & $4,537,864$ & 86 & 12 & 58 & 383 & 134 & 2 & -99 \\
\hline Niger & 31 & 94 & 203 & 63 & 81 & 29 & $2,184,277$ & 92 & 16 & 40 & 150 & 55 & 9 & -84 \\
\hline Philippines & 58 & 48 & -17 & 55 & 90 & 64 & $1,034,080$ & 78 & 58 & 84 & 45 & 281 & 54 & -81 \\
\hline Rwanda & NA & 90 & NA & 81 & 95 & 17 & NA & NA & 31 & 91 & 194 & 5 & 2 & -60 \\
\hline Senegal & 45 & 65 & 44 & 62 & 95 & 53 & 359,845 & 92 & 58 & 68 & 17 & 0 & 6 & NA \\
\hline Sierra Leone & 20 & 90 & 350 & 53 & 90 & 70 & $1,704,814$ & 102 & 37 & 69 & 86 & 36 & 36 & 0 \\
\hline South Africa & 65 & NA & NA & 68 & 90 & 32 & NA & NA & 91 & 97 & 7 & 11 & 0 & -100 \\
\hline Tanzania & 77 & 94 & 22 & 79 & 90 & 14 & 987,575 & 71 & 43 & 64 & 49 & 48 & 0 & -100 \\
\hline Timor-Leste & NA & 68 & NA & NA & 83 & NA & 24,141 & 53 & 18 & 57 & 217 & NA & 1 & NA \\
\hline Togo & 47 & 76 & 62 & 63 & 83 & 32 & 262,130 & 87 & 35 & 45 & 29 & 33 & 14 & -58 \\
\hline Turkey & 36 & 55 & 53 & 50 & 95 & 90 & $1,242,674$ & 58 & 83 & 98 & 18 & 26 & 0 & -100 \\
\hline Uganda & 42 & 66 & 57 & 70 & 85 & 21 & $2,448,527$ & 86 & 39 & 74 & 90 & 470 & 78 & -83 \\
\hline Vietnam & 90 & 88 & -2 & 86 & 94 & 9 & 367,842 & 69 & 59 & 94 & 59 & 142 & 37 & -74 \\
\hline Zambia & 61 & 76 & 25 & 78 & 85 & 9 & 330,030 & 81 & 42 & 63 & 50 & 130 & 71 & -45 \\
\hline Zimbabwe & 60 & 75 & 25 & 76 & 87 & 14 & NA & NA & NA & 78 & NA & 16 & 0 & -100 \\
\hline
\end{tabular}

See table footnotes on the next page.

targeted 201 million women of reproductive age received at least 2 doses of TTCV (4). In 2018, 49 million women remain unreached by TTCV SIAs (Figure 1). Among the 52 countries that conducted TTCV SIAs, $29(56 \%)$ vaccinated $\geq 80 \%$ of the targeted women with $\geq 2$ doses of TTCV (Table). Among the 45 countries that achieved MNT elimination by the end of
2018, 38 (84\%) had conducted TTCV SIAs. Among the seven countries that achieved elimination by the end of 2018 but did not conduct SIAs, six (China, Eritrea, Namibia, Rwanda, South Africa, and Zimbabwe) achieved MNT elimination through strengthening of routine immunization and reproductive health services; one country (Malawi) achieved elimination 
TABLE. (Continued) Estimated coverage with $\geq 2$ doses of tetanus toxoid-containing vaccine (TTCV) among women of reproductive age (WRA) administered through routine immunization services, estimated percentage of newborns protected at birth (PAB), number of WRA vaccinated with TTCV during supplementary immunization activities (SIAs), percentage of deliveries attended by a skilled birth attendant (SBA), and number of reported neonatal tetanus cases - 59 priority countries, 2000-2018

\begin{tabular}{|c|c|c|c|c|c|c|c|c|c|c|c|c|c|c|}
\hline \multirow{3}{*}{$\begin{array}{l}\text { MNT } \\
\text { elimination } \\
\text { priority } \\
\text { countries }\end{array}$} & \multicolumn{3}{|c|}{$\begin{array}{c}\text { WRA TT2+/Td2+ } \\
\text { coverage }(\%)\end{array}$} & \multicolumn{3}{|c|}{ Newborns PAB (\%) } & \multicolumn{2}{|c|}{$\begin{array}{l}\text { WRA vaccinated during } \\
\text { TTCV SIAs* }\end{array}$} & \multicolumn{3}{|c|}{$\begin{array}{c}\text { SBA attendance at } \\
\text { delivery (\%) }\end{array}$} & \multicolumn{3}{|c|}{ No. of neonatal tetanus cases } \\
\hline & \multicolumn{2}{|c|}{ Year } & \multirow{2}{*}{$\begin{array}{c}\text { Change } \\
2000-2018 \\
(\%)\end{array}$} & \multicolumn{2}{|c|}{ Year } & \multirow{2}{*}{$\begin{array}{c}\text { Change } \\
2000-2018 \\
(\%)\end{array}$} & \multirow{2}{*}{$\begin{array}{l}\text { No. of TT2+/ } \\
\text { Td2+ doses } \\
\text { received }\end{array}$} & \multirow{2}{*}{$\begin{array}{c}\% \\
\text { vaccinated }\end{array}$} & \multicolumn{2}{|c|}{ Year $^{\dagger}$} & \multirow{2}{*}{$\begin{array}{c}\text { Change } \\
2000-2018 \\
(\%)\end{array}$} & \multicolumn{2}{|c|}{ Year } & \multirow{2}{*}{$\begin{array}{c}\text { Change } \\
2000-2018 \\
(\%)\end{array}$} \\
\hline & 2000 & 2018 & & 2000 & 2018 & & & & 2000 & 2018 & & 2000 & 2018 & \\
\hline \multicolumn{15}{|c|}{ Not validated for MNT elimination by the end of 2018} \\
\hline Afghanistan & 20 & 85 & 325 & 32 & 68 & 113 & $5,211,872$ & 46 & 14 & 59 & 321 & 139 & 53 & -62 \\
\hline Angola & NA & 66 & NA & 60 & 78 & 30 & $7,097,552$ & 84 & NA & 47 & NA & 131 & 86 & -34 \\
\hline $\begin{array}{l}\text { Central African } \\
\text { Republic }\end{array}$ & 20 & 89 & 345 & 36 & 60 & 67 & 804,984 & 78 & 32 & NA & NA & 37 & 39 & 5 \\
\hline Chad $^{\S}$ & 12 & 69 & 475 & 39 & 78 & 100 & $3,222,840$ & 84 & 14 & 20 & 43 & 142 & 189 & 33 \\
\hline $\begin{array}{l}\text { Democratic } \\
\text { Republic of } \\
\text { the Congo }\end{array}$ & 25 & 96 & 284 & 45 & 85 & 89 & $10,342,937$ & 92 & 61 & 80 & 31 & 77 & 47 & -39 \\
\hline Guinea & 43 & 70 & 63 & 79 & 80 & 1 & $3,545,105$ & 91 & 49 & 55 & 12 & 245 & 107 & -56 \\
\hline Mali & 62 & 60 & -3 & 50 & 85 & 70 & $4,086,957$ & 49 & 41 & 67 & 63 & 73 & 10 & -86 \\
\hline Nigeria & NA & 62 & NA & 57 & 60 & 5 & $4,986,353$ & 84 & 34 & 43 & 26 & 1643 & 130 & -92 \\
\hline Pakistan & 51 & 60 & 18 & 71 & 85 & 20 & $21,143,148$ & 87 & 23 & 69 & 200 & 1380 & 0 & -100 \\
\hline $\begin{array}{l}\text { Papua New } \\
\text { Guinea }\end{array}$ & 10 & 30 & 200 & 24 & 70 & 192 & 450,739 & 15 & 39 & NA & NA & 138 & 0 & -100 \\
\hline Somalia & 22 & 59 & 168 & 47 & 67 & 43 & 497,561 & 27 & 25 & NA & NA & NA & NA & NA \\
\hline South Sudan & NA & 44 & NA & NA & NA & NA & $5,223,306$ & 65 & NA & NA & NA & NA & NA & NA \\
\hline Sudan & 34 & 51 & 50 & NA & 80 & NA & $4,780,345$ & 89 & NA & 78 & NA & 88 & NA & NA \\
\hline Yemen & 31 & 22 & -29 & 54 & 70 & 30 & $3,043,456$ & 52 & 27 & 45 & 67 & 174 & 116 & -33 \\
\hline $\begin{array}{l}\text { All } 59 \text { priority } \\
\text { countries }\end{array}$ & - & - & - & - & - & - & $154,476,411$ & - & - & - & - & 16,754 & 1,760 & - \\
\hline
\end{tabular}

Abbreviations: MNT = maternal and neonatal tetanus; NA = not available; Td2+ = 2 or more doses of tetanus and diphtheria toxoid-containing vaccine; $\mathrm{TT} 2+=2$ or more doses of TTCV.

* Includes first-year SIA conducted in Bangladesh in 1999 and first- and second-year SIAs conducted in Ethiopia in 1999.

+ Includes SBA attendance surveys conducted within 5 years for year 2000 and year 2018.

$\S$ Validated for MNT elimination in 2019.

because women of reproductive age are targeted for vaccination during pregnancy, and 5 TTCV doses are provided in the routine vaccination schedule for children and adolescents. ${ }^{\dagger \dagger \dagger}$

\section{Surveillance Activities}

Reported NT cases and incidence. WHO recommends nationwide case-based surveillance for NT, including zero-case reporting (submission of reports even if no NT cases are seen), active surveillance through regular site visits, and retrospective record review at major health facilities at least once a year (2). During 2000-2018, the number of reported NT cases worldwide (i.e., including nonpriority countries) decreased by $90 \%$ from 17,935 to 1,803 (3). In 2018,13 (22\%) of 59 priority countries reported zero NT cases (Table). The number of NT cases reported annually is likely to represent $<11 \%$ of the actual number of NT cases occurring worldwide annually, because NT tends to occur in remote areas and cases might not be seen by health care workers (5).

\footnotetext{
$\dagger^{\dagger \dagger}$ https://cdn1.sph.harvard.edu/wp-content/uploads/sites/2413/2015/12/ Nina-Schwalbe-1.pdf; https://apps.who.int/iris/bitstream/ handle/10665/232360/WER7901_02_2-6.PDF?sequence=1\&isAllowed=y.
}

NT mortality estimates. Because most NT deaths occur in the community and are not reported to WHO, NT deaths are usually estimated using mathematical models (G). During 2000-2018, the estimated number of NT deaths decreased by $85 \%$ from 170,829 to 25,000 (Figure 2). In 2018, neonatal tetanus accounted for $1 \%$ of major causes of neonatal deaths, a significant decrease compared with a $7 \%$ contribution to all-cause neonatal mortality in 2000.

\section{Deliveries Assisted by Skilled Birth Attendants}

WHO and UNICEF estimate the percentage of births attended by an SBA from health facility reports and coverage survey estimates shared by countries (7). During 2000-2018, the percentage of deliveries attended by an SBA increased by $31 \%$ from $62 \%$ during $2000-2005$ to $81 \%$ during $2013-2018$ (7). In 2018, among 51 priority countries with available data, $\geq 70 \%$ of deliveries were attended by an SBA in $24(47 \%)$ countries (Table).

\footnotetext{
\$SS https://www.unicef.org/media/60561/file/UN-IGME-child-mortalityreport-2019.pdf.
} 
FIGURE 1. Number of women of reproductive age protected by TTCV* received during SIAs, number targeted but not yet vaccinated, number not yet targeted, and number of priority countries achieving maternal and neonatal tetanus elimination - worldwide, 2000-2018

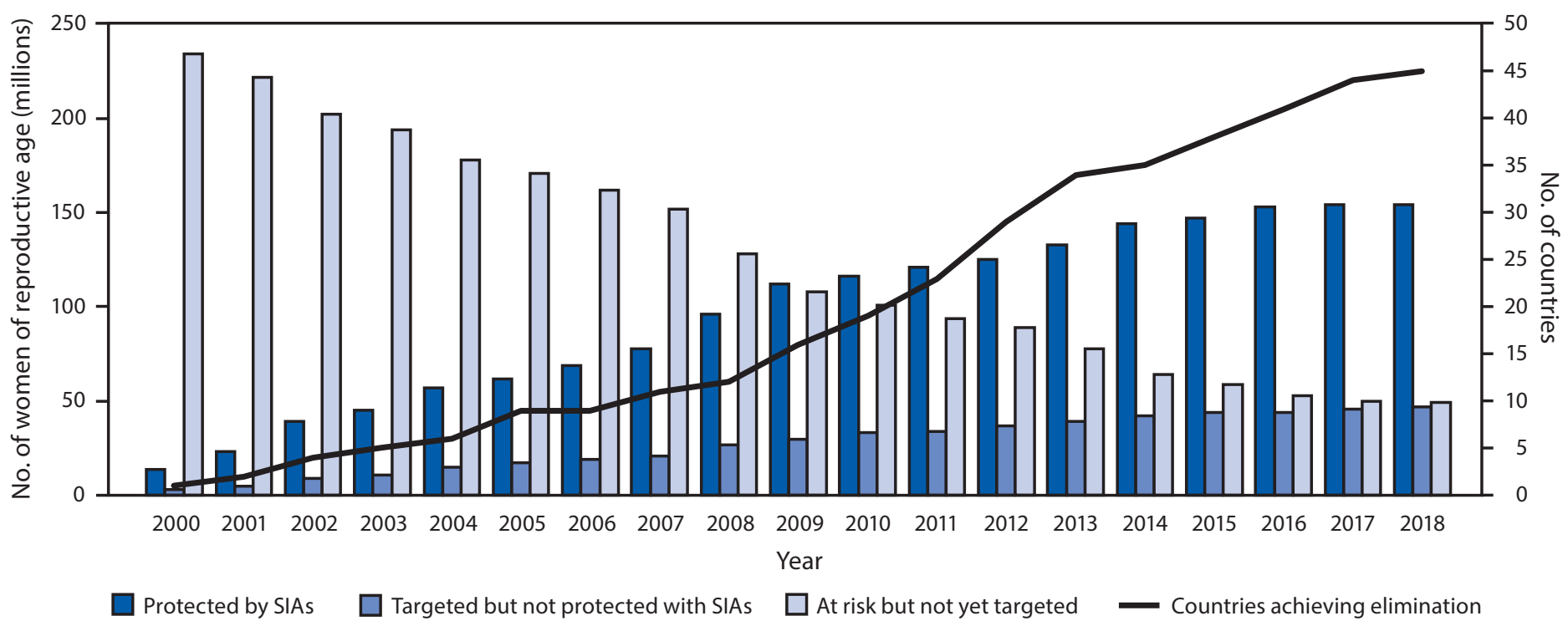

Abbreviations: SIAs = supplementary immunization activities; TTCV = tetanus toxoid-containing vaccine.

* 2 doses of tetanus toxoid (TT) or 2 doses of tetanus and diphtheria toxoids (Td).

FIGURE 2. Estimated number of neonatal tetanus (NT) deaths and estimated coverage with $\geq 2$ doses of tetanus toxoid (TT) or tetanus and diphtheria toxoids (Td)-containing vaccine (TT2+/Td2+) among women of reproductive age - worldwide, 2000-2018

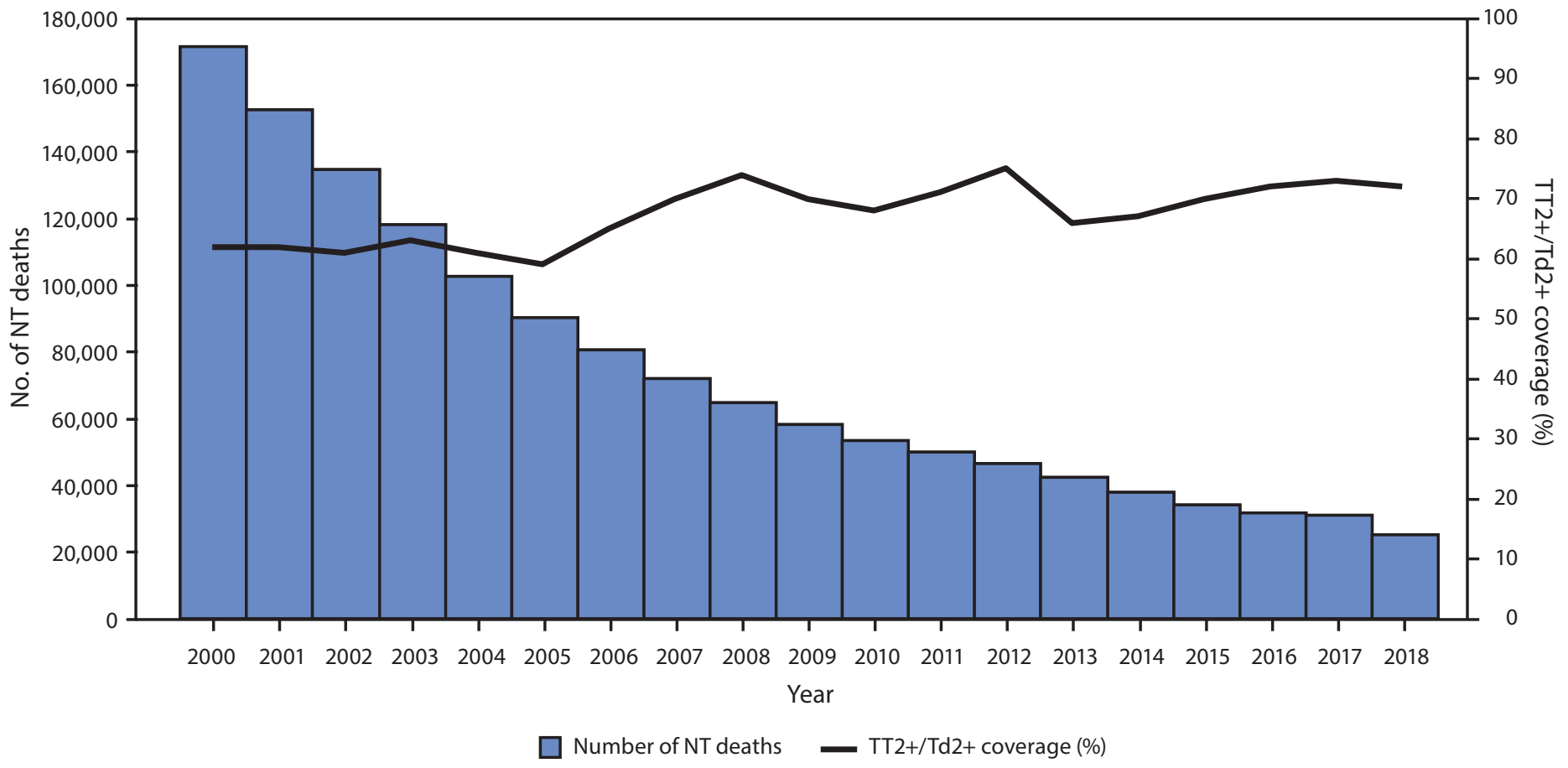

\section{Validation of Maternal and Neonatal Tetanus Elimination}

WHO recommends the validation of MNT elimination when countries complete the implementation of planned elimination activities (8). The validation process involves a review of district-level core indicators, including reported NT cases per 1,000 live births, percentage of deliveries by SBA, TT2+/Td $2+$ coverage, and supplementary indicators, 
including TTCV SIA coverage, antenatal care coverage, 999 infant coverage with 3 doses of diphtheria-tetanus-pertussis vaccine, socioeconomic indices, urban versus rural status, field visits to assess the performance of the health system, validation surveys of districts with the most poorly performing MNT elimination indicators, and assessment of long-term plans for sustaining elimination (9). During 2000-2018, 45 (76\%) of 59 priority countries were validated to have achieved MNT elimination, and $14^{* * * *}$ remain to be validated (Table) (Figure 1). In addition, by 2018 , three countries were validated to have achieved elimination in some regions: Pakistan (Punjab province), Mali (Southern regions), and Nigeria (South East zone).

\section{Discussion}

There has been significant progress globally to eliminate MNT, and approximately $75 \%$ of the 59 priority countries were validated to have achieved MNT elimination by the end of 2018. The intensive targeting of "high-risk areas and districts" reached an estimated 154 million women of reproductive age with at least 2 doses of TTCV through SIAs, resulting in an $85 \%$ decline in the number of NT deaths annually during 2000-2018. Critical factors contributing to success include improvement in women's access to education, country commitment to the implementation of recommended elimination strategies, timely availability of resources, good planning for SIAs, community engagement in elimination activities, strong monitoring and supervision of MNT elimination activities, and integrated delivery of antenatal care and tetanus vaccination services. Once countries are validated to have achieved MNT elimination, efforts to sustain elimination and broader tetanus control should continue, because tetanus cannot be eradicated from the environment.

MNT elimination validation assessments conducted in Cameroon and Timor-Leste, as well as Algeria and Djibouti (both validated before the 1999 relaunch of the initiative), showed that elimination was sustained; however, access to SBAs needed to be improved in Cameroon and Timor-Leste. Critical strategies for sustaining MNT elimination include strengthening routine immunization services for children and adolescents to receive a 3 -dose primary TTCV series, and 3 TTCV booster doses at ages 12-23 months, 4-7 years, and 9-15 years to ensure long-term protection; antenatal screening of pregnant women for tetanus vaccination to ensure protection of neonates at birth; increased access to SBAs and clean delivery and cord care practices; strong tetanus surveillance;

999 Antenatal care coverage is the percentage of women aged 15-49 years with a live birth who had received antenatal care provided by skilled health personnel (doctor, nurse, or midwife) at least once during the pregnancy.

**** Chad and the Democratic Republic of the Congo were validated in 2019, leaving 12 countries not validated by December 2019.

\section{Summary \\ What is already known about this topic?}

In 1999, the maternal and neonatal tetanus (MNT) elimination initiative was relaunched to focus on 59 priority countries that were still at risk for neonatal tetanus (NT).

What is added by this report?

During 2000-2018, 45 countries achieved MNT elimination, reported NT cases decreased $90 \%$, and estimated deaths declined $85 \%$. Despite this progress, some countries that achieved elimination are still struggling to sustain performance indicators; war and insecurity pose challenges in countries that have not achieved MNT elimination.

What are the implications for public health practice?

To maintain MNT elimination and to achieve it in remaining priority countries, sustained efforts are needed to enhance routine vaccination, embrace life-course vaccination, and develop innovative strategies for reaching underserved populations.

and periodic review of data to identify districts that are at risk for reemergence of MNT (2).

The findings in this report are subject to at least two limitations. First, TT2+/Td $2+$ coverage can underestimate true protection from tetanus, especially in countries with wellestablished vaccination programs, because it excludes women who were unvaccinated during pregnancy but were already protected through previous vaccination or had undocumented previous doses (10). Therefore, the percentage of PAB needs to be assessed, especially in countries that have achieved MNT elimination. Second, the number of neonatal tetanus cases and deaths are an underestimate of the actual number of NT cases because the majority of deaths occur in communities in areas underserved by the health care system (5).

Despite the progress made, the MNT elimination initiative still faces numerous challenges. Approximately 47 million women and their babies remain unprotected against tetanus, and 49 million women remain unreached by TTCV SIAs. Low TT2+/Td $2+$ coverage in these countries can be attributed to weak health systems, including conflict and security issues that limit access to vaccination services, competing priorities that limit the implementation of planned MNT elimination activities, and withdrawal of donor funding. Promoting institutional deliveries and ensuring the availability of clean delivery kits ${ }^{\dagger \dagger \dagger \dagger}$ for every home delivery would help MNT elimination and efforts to achieve the United Nations' Sustainable Development Goal 3 to reduce maternal and neonatal mortality (https:// www.un.org/sustainabledevelopment/health/). Innovative approaches to reach remote and unsafe areas could include

††† https://www.unfpa.org/sites/default/files/resource-pdf/RH\%20kits\%20 manual_EN_0.pdf. 
the use of compact, prefilled autodisable devices; integration of reproductive, maternal, newborn, and child health services with vaccination services to optimize maternal immunization; and integration of TTCV SIAs with other SIAs, such as serogroup A meningococcal vaccine (MenA), measles-rubella, yellow fever, and polio campaigns. Efforts to strengthen NT surveillance through community engagement could serve as a platform for creating community-based surveillance systems for other diseases, and case-based surveillance for NT could be integrated with polio and measles case-based surveillance. ${ }^{\$ \$ \$ \$}$

\$SS\$ https://www.who.int/immunization/monitoring_surveillance/burden/vpd/ WHO_SurveillanceVaccinePreventable_14_NeonatalTetanus_R1.pdf.

\section{Acknowledgment}

United Nations Children's Fund (UNICEF) country offices in Yemen, Nigeria, Pakistan, South Sudan, Guinea; UNICEF regional officers: Mehoundo Faton, West and Central Africa Regional Office; Daniel Ngemera, Middle East and North Africa Regional Office. World Health Organization offices in the 45 MNT-validated countries and their regional offices counterparts.

Corresponding author: Henry N. Njuguna, vkc7@cdc.gov, 404-718-3535.

${ }^{1}$ Global Immunization Division, Center for Global Health, CDC;

${ }^{2}$ Immunization, Vaccines and Biologicals, World Health Organization, Geneva,

Switzerland; ${ }^{3}$ Maternal, Newborn, and Adolescent Health Program Division,

UNICEF, New York, New York.

All authors have completed and submitted the International Committee of Medical Journal Editors form for disclosure of potential conflicts of interest. No potential conflicts of interest were disclosed.

\section{References}

1. United Nations Children's Fund, World Health Organization, United Nations Population Fund. Maternal and neonatal tetanus elimination by 2005: strategies for achieving and maintaining elimination. New York, NY: United Nations Children's Fund; Geneva, Switzerland: World Health Organization; New York, NY: United Nations Population Fund; 2000. https://www.unicef.org/french/health/files/MNTE_strategy_paper.pdf

2. World Health Organization. Protecting all against tetanus: guide to sustaining maternal and neonatal tetanus elimination and broadening tetanus protection for all populations. Geneva, Switzerland: World Health Organization; 2019. https://apps.who.int/iris/bitstream/hand le/10665/329882/9789241515610-eng.pdf?ua=1

3. World Health Organization, United Nations Children's Fund. Immunization, vaccines and biologicals: data, statistics and graphics. Geneva, Switzerland: World Health Organization; New York, NY: United Nations Children's Fund; 2019. https://www.who.int/immunization/ monitoring_surveillance/data/en/

4. World Health Organization. Immunization, vaccines and biologicals: maternal and neonatal tetanus elimination. Geneva, Switzerland: World Health Organization; 2019 http://www10.who.int/immunization/ diseases/MNTE_initiative/en/index7.html

5. Khan R, Vandelaer J, Yakubu A, Raza AA, Zulu F. Maternal and neonatal tetanus elimination: from protecting women and newborns to protecting all. Int J Womens Health 2015;7:171-80.

6. Roper MH, Vandelaer JH, Gasse FL. Maternal and neonatal tetanus. Lancet 2007;370:1947-59 https://doi.org/10.1016/S0140-6736(07)61261-6

7. United Nations Children's Fund (UNICEF), World Health Organization (WHO). UNICEF/WHO joint database: delivery at care. New York, NY: UNICEF; 2019. https://data.unicef.org/topic/maternal-health/ delivery-care/

8. World Health Organization. Validation of maternal and neonatal tetanus elimination. Geneva, Switzerland: World Health Organization; 2014. https://www.who.int/immunization/documents/MNTE_Validation_ survey_WHO_IVB_18.15.pdf

9. World Health Organization. Maternal and neonatal tetanus elimination (MNTE): validating MNT elimination. Geneva, Switzerland: World Health Organization; 2020. https://www.who.int/immunization/ diseases/MNTE_initiative/en/index2.html

10. World Health Organization. Protection-at-birth method, Tunisia: monitoring tetanus toxoid coverage and avoiding missed opportunities for tetanus toxoid vaccination. Wkly Epidemiol Rec 2000;75:203-6. 